\title{
Comportamento cinético do fermentado alcoólico de banana prata (musa ssp) frente a diferentes parâmetros
}

\section{Cinetic behavior of fermented alcoholic silver banana (musa spp) against different parameters}

\author{
Manoel Tolentino Leite Filho ${ }^{\text {; Emmanuel Moreira Pereira }}{ }^{1}$; Eliane Rolim Florentino ${ }^{2}$; Mario Eduardo Rangel Moreira \\ Cavalcanti Mata ${ }^{3}$, Bárbara Bruna Maniçoba Pereira ${ }^{4}$.
}

\begin{abstract}
Resumo: Dentre as frutas fermentescíveis que podem ser utilizadas na elaboração de bebidas fermentadas (bebidas alcoólicas), a banana se destaca devido a sua abundância e concentração relativamente elevada de açúcares. O trabalho teve por objetivo desenvolver e avaliar o rendimento e a qualidade físico-química de um novo produto: o fermentado alcoólico de banana. Foi elaborado um protótipo do produto, utilizando a variedade de banana prata, cuja fruta foi comprada no mercado local da cidade de Campinha Grande - PB. Foi feito um tratamento térmico a $120^{\circ} \mathrm{C}$ por $15 \mathrm{~min}$. O teor de sólidos solúveis do caldo foi de 12,5 ${ }^{\circ}$ Brix e estes foram inoculados com levedura do gênero (Saccharomyces cerevisiae) em frascos de Erlenmeyer, à temperatura ambiente. Após $9 \mathrm{~h}$, a fermentação cessou. As análises físico-químicas foram realizadas a cada 1 h. O teor alcoólico final obtido foi de $3,75^{\circ} \mathrm{GL}$, o $\mathrm{pH}$ final foi de 4,1 , os sólidos solúveis ${ }^{\circ}$ brix ficaram em torno de 3,4 os açúcares redutores totais ficaram em torno de $3,5 \mathrm{~g} / \mathrm{L}$ e o crescimento da biomassa foi de $0,48 \mathrm{~g} / \mathrm{L}$.
\end{abstract}

Palavras-chaves: Musa ssp; Saccharomyces cerevisiae; Novos produtos.

\begin{abstract}
Among the fermentable fruits that can be used in the preparation of fermented beverages (alcoholic), banana stands out due to its abundance and relatively high sugar concentration. The study aimed to develop and evaluate the performance and the physical and chemical quality of a new product: the alcoholic fermented banana. A prototype of the product was prepared using a variety of silver banana whose fruit was bought at the local market town of Campina Grande - PB. A heat treatment was done at $120^{\circ} \mathrm{C}$ for $15 \mathrm{~min}$. The soluble solids content of the broth was $12.5^{\circ}$ Brix and those of the genus were inoculated with yeast (Saccharomyces cerevisiae) in Erlenmeyer flasks at room temperature. After 9 hours, the fermentation ceased. The physicochemical analyzes were performed every $1 \mathrm{~h}$. The final strength, obtained was $3.75^{\circ} \mathrm{GL}$, the final $\mathrm{pH}$ was 4.1 , the soluble solids brix were around 3.4 total reducing sugars were around $3.5 \mathrm{~g} / \mathrm{L}$ and growth of the biomass was $0.48 \mathrm{~g} / \mathrm{L}$.
\end{abstract}

Keywords: Musa spp; Saccharomyces cerevisiae; New products.

\footnotetext{
*Autor para correspondência

Recebido para publicação em 18/09/2015; aprovado em 10/10/2015

${ }^{1}$ Pós-graduando em Engenharia Agrícola - UFCG/CTRN - Universidade Federal de Campina Grande, E-mail: manoelqi2009.1@gmail.com; emmanuel16mop@hotmail.com

${ }^{2}$ Professora Pesquisadora - UEPB/CCT - Universidade Estadual da Paraíba

${ }^{3}$ Professor Pesquisador - UFCG/CTRN - Universidade Federal de Campina Grande

${ }^{4}$ Doutoranda em Engenharia de Processos - UFCG - Universidade Federal de Campina Grande, E-mail: barbara.bmp@hotmail.com
} 


\section{INTRODUÇÃO}

A produção de bebidas fermentadas no Brasil tem seu início no período da colonização. Tudo começou entre 1532 e 1548, quando Martin Afonso de Sousa introduziu a cana-deaçúcar no Brasil, e onde por acaso foi descoberto o "vinho" da cana-de-açúcar, conhecido como "garapa azeda da cana". Além da cana-de-açúcar, o Brasil apresenta inúmeras matérias-primas que potencialmente servem para conversão em bebidas alcoólicas que poderiam concorrer com a aguardente de cana. Entre as matérias-primas, destacam-se, pelos seus teores de açúcares fermentescíveis e características sensoriais, várias frutas disponíveis no território brasileiro, como por exemplo: abacaxi, manga, banana e goiaba. Entre as frutas com potencial de conversão em aguardente, a banana aparece como uma boa opção, em especial devido a sua disponibilidade em quase todo o território brasileiro e seus atrativos sensoriais, destacando o aroma agradável. Em relação ao seu potencial para conversão em aguardente, a banana apresenta teor relativamente elevado em carboidratos, na forma de glicose, sacarose, frutose e amido, cujos percentuais dependem do estádio de maturação da fruta (ALVES, 1997).

A elaboração de bebidas alcoólicas é um dos processos mais antigos que acompanham as civilizações. A utilização de sucos de frutas para elaboração de bebidas alcoólicas tem sido uma forma de aproveitamento, evitando assim o desperdício quando não se tem um consumo imediato, como também pode agregar valor às bebidas regionais (FILHO, 2010).

A banana é a segunda fruta mais produzida no Brasil e a primeira mais consumida no mundo (EMBRAPA, 2009). É extremamente rica em potássio, carboidratos e fibras solúveis, além de conter fósforo, cálcio, magnésio e vitaminas A, B e C. Destaca-se também pelo elevado teor de açúcares, pela multiplicidade de uso, excelente sabor e ampla aceitação entre todas as faixas etárias e níveis sociais. a banana é uma fruta que produz o ano todo possibilitando que seja fornecida ao mercado com a regularidade que é requerida (TEIXEIRA, 2004).

\section{MATERIAISE MÉTODOS}

O presente trabalho foi desenvolvido no Núcleo de Pesquisa em Alimentos (NUPEA), pertencente ao Departamento de Química do Centro de Ciências e Tecnologias da Universidade Estadual da Paraíba (UEPB). Para a produção do fermentado alcoólico de banana, foram utilizadas bananas da variedade Prata, obtidas no comercio local da cidade de Campina Grande - PB. Para a fermentação foi utilizada a levedura Saccharomyces cerevisiae sob a forma de fermento granulado seco, produzido pela Anguest. Para preparação do mosto, as bananas foram selecionadas, sanitizadas em solução de hipoclorito de sódio a $1 \%$, descascadas manualmente, trituradas em liquidificador industrial, diluída em água destilada até atingir $12,5{ }^{\circ} \mathrm{Brix}$, pasteurizado em Autoclave a $120^{\circ} \mathrm{C}$, por 15 minutos, a fim de evitar escurecimento do mesmo, resfriado a temperatura ambiente e inoculado 5\% da Saccharomyces cerevisiae. Para fermentação, adicionou-se diretamente no mosto de banana, o fermento liofilizado contendo cepas de $S$. cerevisiae, na proporção de $5 \%$ do volume, agitando-o até que a levedura fosse completamente dispersa no meio. $\mathrm{O} \mathrm{pH}$ foi corrigido de 3,9 para 4,3 adicionando hidróxido de sódio. A fermentação ocorreu em frasco de Erlenmeyers com capacidade de 2000 $\mathrm{mL}$, em modo batelada simples sem agitação a temperatura ambiente $\left( \pm 28^{\circ} \mathrm{C}\right)$ e teve duração de 9 horas. Amostras em tempos regulares ( 1 em 1 hora) eram coletadas para acompanhar o crescimento celular, $\mathrm{pH},{ }^{\circ} \mathrm{Brix}$, teor alcoólico e Açúcares redutores totais durante todo processo fermentativo, conforme Figura 1.

Figura 1. Fluxograma de produção do fermentado de banana prata (musa ssp).

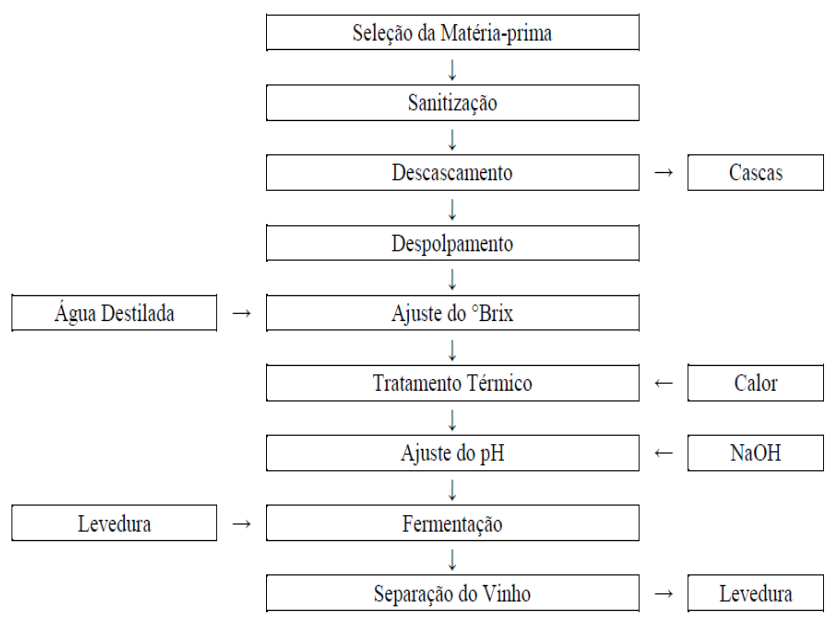

\section{RESULTADOS E DISCUSSÃO}

Na produção do fermentado de banana, no processo de fermentação alcoólica, foram obtidos dados experimentais referentes às concentrações de substrato (sólidos solúveis totais), teor alcoólico do vinho, biomassa (microrganismo), açúcares redutores totais (ART) e $\mathrm{pH}$, em intervalos de 1 horas, durante um período de 9 horas.O perfil cinético reproduzido no experimento de fermentação alcoólica de mosto de banana, representado pela variação das concentrações de sólidos solúveis totais ( ${ }^{\circ}$ Brix) e do teor alcoólico ( $\left.{ }^{\circ} \mathrm{GL}\right)$ ao longo do tempo de fermentação, estão ilustrados na Figura 2.

Figura 2: Evolução dos valores de sólidos solúveis totais ( ${ }^{\circ}$ Brix) e do teor alcoólico $\left({ }^{\circ} \mathrm{GL}\right)$ durante o processo fermentativo.

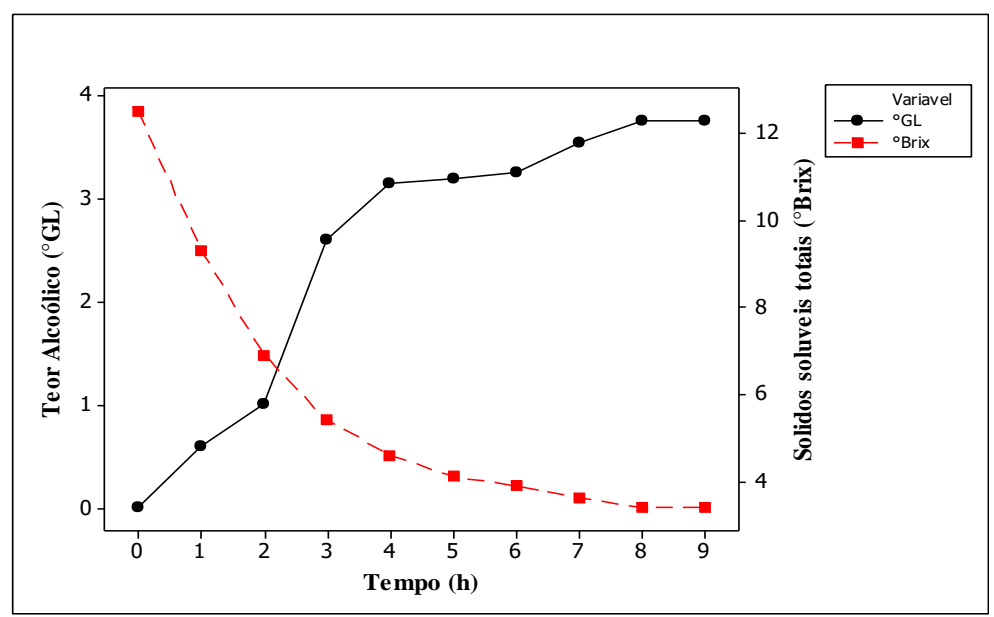


Analisando os resultados do teor de sólidos solúveis totais na Figura 2, é observada a metabolização do substrato pelas leveduras nas quatro primeiras horas de processo. Ficou evidenciada a curta fase de adaptação das células (fase lag) que sob o ponto de vista industrial deve ocorrer sempre, pois a fermentação ocorrera mais rapidamente evitando assim que possíveis contaminantes possam se desenvolver. Apesar de o agente fermentativo não ter sido previamente adaptado no mesmo meio de cultivo, observou-se que as mesmas não apresentaram dificuldades de se adaptarem ao meio. Nos processos fermentativos industriais as células inoculadas devem se encontrar na fase exponencial de crescimento para que estejam metabolitamente ativas (AQUARONE; LIMA; BORZANI, 1983). Ressalta-se que nesse mesmo Experimento, as células metabolizaram os açúcares presentes numa taxa constante de produção de álcool imediatamente após a inoculação. A produção máxima de etanol $\left(3,75^{\circ} \mathrm{GL}\right)$ foi detectada com 8 horas de cultivo assim como as leveduras tenham degradado os sólidos solúveis até 8 horas, momento em que a proporção de sólidos solúveis atingiu $3,4^{\circ}$ Brix.

Ainda na Figura 2, foram observados que nas primeiras 4 horas de fermentação houve decaimento acentuado dos sólidos solúveis de 12,5 a 4,6 ${ }^{\circ}$ Brix. Após as 8 horas de fermentação houve a estabilização do mesmo em um valor igual a 3,4 ${ }^{\circ}$ Brix. Normalmente, espera-se que a fermentação alcoólica acuse atenuação completa dos sólidos solúveis $\quad 0^{\circ}$ Brix (LIMA, 2001). Entretanto, este comportamento não foi observado no presente trabalho.

Acredita-se que a hidrólise do mosto e sua suplementação com nutrientes extras (vitaminas, sais minerais, etc.) contribuiriam para se obter um comportamento de fermentação mais próximo do esperado. A hidrólise resultara na quebra do amido em açucares simples possibilitando que os mesmos sejam consumidos pelos microrganismos presente (SANTOS, 2008). A figura 3 mostra o perfil cinético reproduzido no experimento de fermentação alcoólica de mosto de banana, representado pela variação das concentrações de ART $(\mathrm{g} / \mathrm{L})$ e do teor alcoólico $\left({ }^{\circ} \mathrm{GL}\right)$ ao longo do tempo de fermentação.

Figura 3: Evolução dos valores de ART (g/L) e do teor alcoólico $\left({ }^{\circ} \mathrm{GL}\right)$ durante o processo fermentativo.

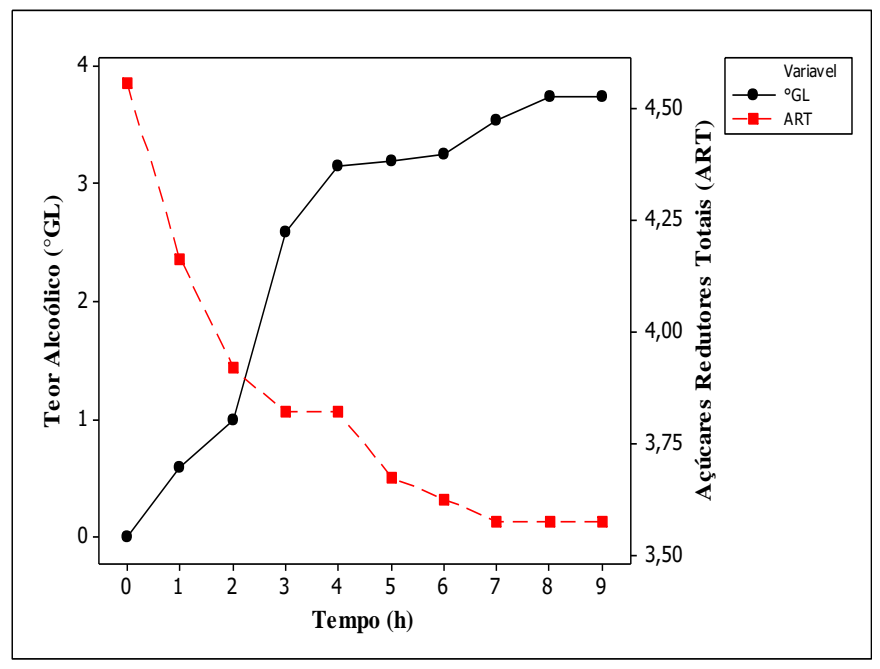

Analisando a Figura 3 verifica-se que houve uma redução brusca na concentração de ART nas primeiras 2 horas da fermentação e após esse período o decaimento foi moderado ate estabilizar com aproximadamente 8 horas.

Na Figura 3 observa-se ainda, que os valores de ART decrescem de 4,573 para 3,54 g/L, ou seja, ocorre uma redução de 22,5\% no valor de ART. Essa redução de ART durante o processo fermentativo também foi observado por Santos (2008) e isso implica para nosso estudo numa produção de $3,75^{\circ} \mathrm{GL}$, durante todo o processo.

A figura 4 mostra o perfil cinético reproduzido no experimento de fermentação alcoólica de mosto de banana, representado pela variação da multiplicação da Saccharomyces cerevisiae $(\mathrm{g} / \mathrm{mL})$ ao longo do tempo de fermentação.

Figura 4: Multiplicação da Saccharomyces cerevisiae ao longo do tempo da fermentação.

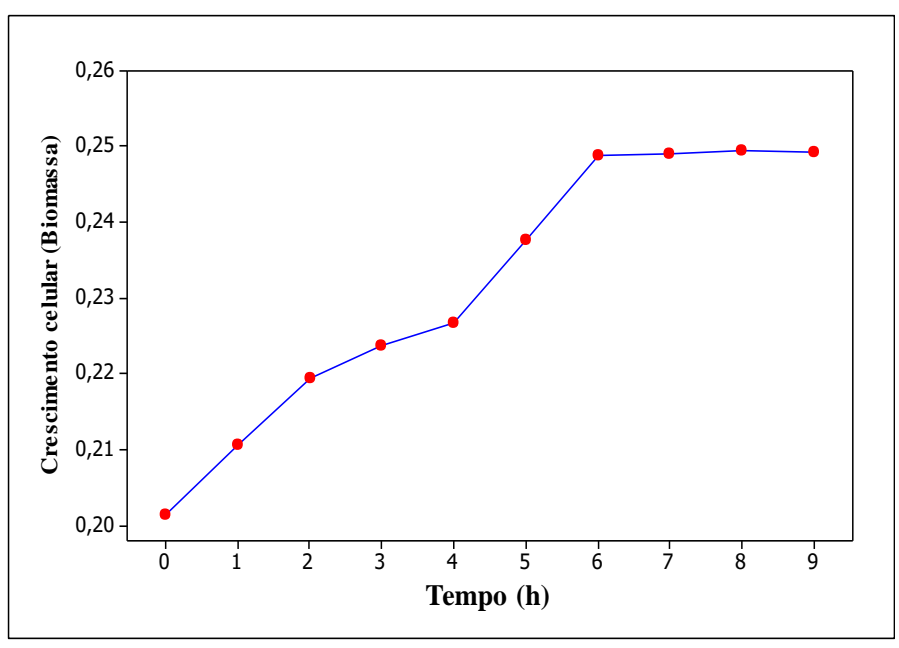

A levedura Saccharomyces cerevisiae mostrou uma rápida multiplicação nas 4 horas iniciais de fermentação no mosto, logo após este período, verificou-se um crescimento mais acentuado da concentração celular ao longo do processo fermentativo não sendo observada a fase lag certamente devido à adaptação dos microrganismos ao meio de cultivo $\mathrm{A}$ multiplicação acentuada na fase inicial se dá pela grande disponibilidade de substrato e a ausência de inibidores. Após as 6 horas de fermentação podem observar uma multiplicação menos acentuada uma vez que a quantidade substrato disponível é menor e o produto já causa inibição moderada na multiplicação da biomassa.

A concentração celular de $0,25 \mathrm{~g} / \mathrm{L}$ de massa seca foi alcançada apos 8 horas de fermentação. A fermentação no mosto de banana pela levedura Saccharomyces cerevisiae mostrou ser rápida ocorrendo em apenas 8 horas da fermentação. Após este período a multiplicação foi diminuindo até alcançar a fase estacionária, entre 8 e 9 horas de fermentação. Fato esse ocorrido também no estudo de Mamede e Pastore (2004), utilizando mosto de uva e leveduras selvagens selecionadas.

A figura 5 mostra o perfil cinético reproduzido no experimento de fermentação alcoólica de mosto de banana, representando o comportamento do $\mathrm{pH}$ ao longo do tempo de fermentação. 
Figura 5: comportamento do $\mathrm{pH}$ ao longo do tempo da fermentação.

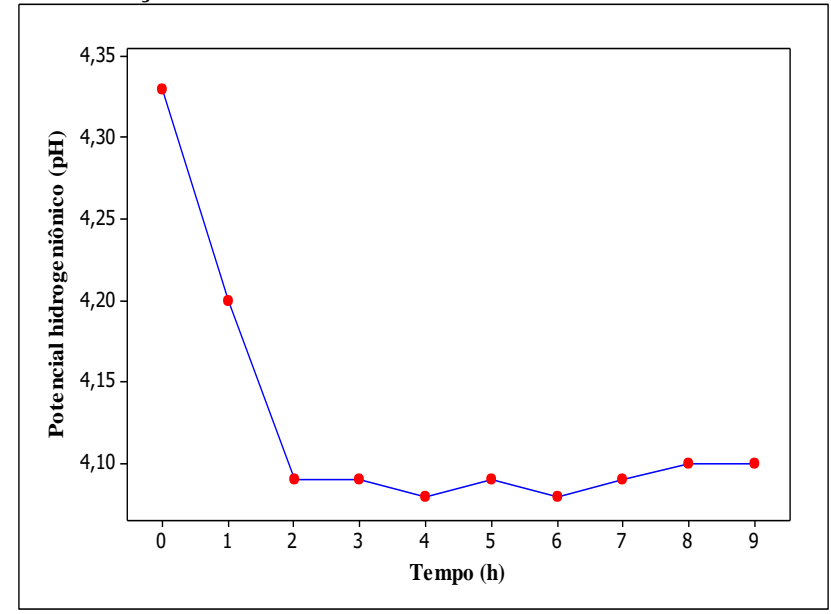

O valor de $\mathrm{pH}$ no tempo zero foi de 4,33, e o mesmo diminuí gradativamente até 4,08 com 8 horas de fermentação (figura 5.4). $\mathrm{O}$ pH desejável numa fermentação para obtenção de aguardente está entre 4,0 e 5,0 (SEBRAE, 2002). Uma das vantagens da utilização de banana como matéria-prima para produção de aguardente é o caráter ácido dessa fruta (3,9 a 4,7), que inibe uma maior contaminação por bactérias (AQUARONE; LIMA; BORZANI, 1983). A máxima produção de ácidos pelas leveduras ocorreu nas 2 horas iniciais do processo fermentativo, permanecendo praticamente constante ou com levés oscilações até o fim do processo. Essas substâncias resultantes de metabolismo secundário da fermentação alcoólica interferem diretamente na qualidade do produto final devido à possibilidade de formação de ésteres responsáveis pelo "bouquet" da bebida dos ácidos succínico, lático, acético, dentre outros (SILVA, 2004).

Oliveira et al. (2001) detectaram diminuição do pH na produção de bebida alcoólica, utilizando pupunha, fruto amiláceo da Região Amazônica.

\section{CONCLUSÔES}

Nas condições deste trabalho, por meio dos resultados obtidos, pode-se concluir que: Durante todo o processo fermentativo ocorreu decréscimo dos valores de sólidos solúveis totais ( $\left.{ }^{\circ} \mathrm{Brix}\right)$. Os mesmos tornaram-se estáveis na ultima hora de fermentação. O teor alcoólico manteve-se crescente durante todo o processo, estabilizando-se a partir da 8 horas de fermentação. O período de fermentação de 9 horas para o mosto de banana madura 'Prata' foi mais que suficiente, em função da transformação praticamente total do açúcar em etanol. O baixo rendimento da produção de aguardente de banana pode ser atribuído, principalmente pelo desdobramento incompleto dos açúcares do mosto de banana (Brix final de 3,4 em média). O desdobramento incompleto dos açúcares do mosto, por sua vez, pode ser justificado, principalmente, pela baixa difusão de $\mathrm{CO} 2$ gerado na fermentação.

\section{REFERÊNCIAS BIBLIOGRÁFICAS}

ALVES, E.J. A cultura da banana - aspectos técnicos, sócio econômico e agroindústrias, Rio de Janeiro: EMBRAPA, 545-585, 1997;

AQUARONE, E.; LIMA, U.A.; BORZANI, W. (1983) Alimentos e bebidas produzidas por fermentação, São Paulo: Ed. Edgard Blucher Ltda. Série Biotecnologia, v.5, p. 79-103;

EMBRAPA (2009) Dia de Campo aborda a cultura da Banana. Disponivel em < http://www.embrapa.br/imprensa/noticias/2009/abril/4semana/dia-de-campo-aborda-acultura-dabanana/?searchterm=banana>

FILHO, W. G. V. Bebidas Alcoólicas: Ciências e Tecnologia. Blucher: São Paulo, p. 87-111. 2010.

LIMA, U. A. Aguardentes. In: AQUARONE, E., LIMA, U.A.; BORZANI, W. (Coord.) Biotecnologia Industrial vol 4: alimentos e bebidas produzidos por fermentação. São Paulo: Edgard Blücher, 2001. v. 5. p. 145-182.

MAMEDE, M. E; PASTORE, G. M, Avaliação da Produção dos Compostos Majoritáriosda Fermentação de Mosto de Uva Por Levedurasisoladas da Região da "Serra Gaúcha" (Rs). Ciênc. Tecnol. Aliment., Campinas,2004.

OLIVEIRA, L.P. de; MAEDA, R.; JUNIOR. N.P.; CARVALHO, S.M. da S.; FILHO, S.A. Processo fermentativo para produção de bebidas. Biotecnologia. Ciência e Desenvolvimento, 2001. p. 50-54;

SANTOS, A. M. Estudo da influência da complementação de nutrientes no mosto sobre o processo de fermentação alcoólica em batelada. Dissertação de mestrado. Universidade federal de Alagoas. 2008.

SEBRAE. Cadeia produtiva da pequena produção dos derivados da cana-de-açúcar de Pernambuco: rapadura, mel, açúcar mascavo e aguardente. Recife: 2002, 104 p.

SILVA, E.F. Obtenção de aguardente de banana em microescala: caracterização do processo e do produto. Dissertação (Mestrado em Ciência e Tecnologia de Alimentos). Universidade Federal da Paraíba, João Pessoa, PB. 2004.

TEIXEIRA, L. J. Q. Avaliação Tecnológica de um processo de produção de licor de banana.81 p. Viçosa: Universidade Federal de Viçosa, 2004. (Dissertação, Mestrado em Ciência eTecnologia de Alimentos). 